\title{
Running Behaviors in a Convenience Sample of Pregnant Women: A Descriptive Study
}

\author{
Jennifer Huberty, PhD RYT ${ }^{1 *}$, Mariah Sullivan ${ }^{1}$, Jeni Green, MS ${ }^{1}$, Anna M. Gorczyca, PhD', \\ Jenn Leiferman, $\mathrm{PhD}^{3}$ and Kisti Fuller ${ }^{4}$
}

${ }^{1}$ College of Health Solutions, Arizona State University, USA

${ }^{2}$ Department of Internal Medicine, University of Kansas Medical Center, USA

${ }^{3}$ Associate Professor, Colorado School of Public Health, USA

${ }^{4}$ Phoenix Perinatal Associates, Arizona, USA

*Corresponding author: Jennifer Huberty, PhD RYT, College of Health Solutions, Arizona State University, USA

\begin{abstract}
Background: No studies have described running behavior in pregnant women who self-identify as runners despite the benefits of moderate to vigorous activity during pregnancy. The purpose of this study was to learn more about behaviors, barriers, and advice health care providers (HCPs) offered regarding running during their pregnancy.

Methods: The study was cross-sectional with national recruitment using internet-based strategies. Eligible women $(\mathrm{N}=189)$ completed an online survey that assessed their health (i.e., height, weight, chronic health conditions) and pregnancy (i.e., trimester, parity); running patterns (e.g. frequency, duration, intensity) prior to, during, and/or post pregnancy; changes in running patterns throughout; barriers to running; and HCP's recommendations for running.
\end{abstract}

Results: Approximately $88 \%(n=166 / 189)$ reported their running patterns changed for reasons including fatigue ( $\mathrm{n}$ $=121 / 166)$, or pelvic $(n=39 / 166)$ or joint/muscle pain $(n$ $=30 / 166$ ). Women on average reported running $100 \pm 42$ $\mathrm{min} / \mathrm{wk}$ in the year before pregnancy, $77 \pm 42 \mathrm{~min} / \mathrm{wk}$ during the $1^{\text {st }}$ trimester, $101 \pm 32 \mathrm{~min} / \mathrm{wk}$ during the $2^{\text {nd }}$ trimester, and $49 \pm 44 \mathrm{~min} / \mathrm{wk}$ during the $3^{\text {rd }}$ trimester. Seventy-five percent $(n=142 / 166)$ had conversations with their HCP about running during pregnancy; $89 \%(n=126 / 142)$ initiated this conversation.

Conclusion: This study contributes to what is known about running patterns during pregnancy, may help guide future recommendations and interventions for pregnant women.

\section{Keywords}

Pregnancy, Physical activity, Healthcare provider, Trimester, Body mass index

\begin{abstract}
Abbreviations
BMI: Body Mass Index; ACOG: American College of Obstetrics and Gynecology; HCP: Health Care Provider
\end{abstract}

\section{Introduction}

It is well established that regular physical activity during pregnancy is safe and beneficial to the mother and the fetus [1,2]. Current physical activity recommendations for pregnant women suggest at least 150 minutes per week of moderate-intensity aerobic activity (e.g., brisk walk) [3]. The American College of Obstetrics and Gynecology (ACOG) recommend that pregnant women engage in moderate intensity physical activity (e.g., walking, swimming, cycling; 3-6 METS) when there are no known obstetrical complications in which exercise is contraindicated $[3,4]$ Strength training and vigorous activities such as running (i.e. high intensity; greater than 6 METS) may be safe if women participated in those activities prior to becoming pregnant [3].

Studies suggest that more than $50 \%$ of pregnant women do not participate in the recommended physical activity levels [5], however studies suggest $50-80 \%$ of pregnant women fail to meet the recommended amounts of physical activity [6,7]. Women fail to participate in physical activity due to nausea and fatigue, and physical pain or discomfort, such as pelvic or low back pain $[8,9]$. In particular, during the third trimester,

Citation: Huberty J, Sullivan M, Green J, Gorczyca AM, Leiferman J, et al. (2021) Running Behaviors in a Convenience Sample of Pregnant Women: A Descriptive Study. Int J Womens Health Wellness 7:120. doi.org/10.23937/2474-1353/1510120

Accepted: June 22, 2021: Published: June 24, 2021

Copyright: (C) 2021 Huberty J, et al. This is an open-access article distributed under the terms of the Creative Commons Attribution License, which permits unrestricted use, distribution, and reproduction in any medium, provided the original author and source are credited. 
a woman's physical size increase and weight gain makes it challenging to be active [5]. Additionally, women may not participate in physical activity for safety reasons (i.e., not knowing if the activity they are doing is safe, or feeling unsafe during an activity) [3]. A majority of studies suggest that physical activity decreases throughout pregnancy with most women being more sedentary in their third trimester as compared to the first and second trimesters $[10,11]$. Women who participate in vigorous activity during pregnancy (only about 5\%; [12]) also participate in less activity as their pregnancy progresses but often regain their previous physical activity patterns during the postpartum period $[13,14]$.

Similar to moderate intensity activity, there are many advantages of vigorous activity during pregnancy. These include reduced likelihood of preterm birth [15], reduced risk of gestational diabetes, insulin resistance $[16,17]$, preeclampsia, and reductions in fat mass [17]. Vigorous activity in these studies was also found to not have significant safety concerns for women whose pregnancies were not considered high-risk $[16,17]$. The exploration of participation in vigorous activity during pregnancy is warranted.

Running is a less studied type of vigorous activity may have beneficial effects on the mother and fetus and may be considered safe during healthy pregnancies [3]. In studies of mothers who run during pregnancy, adverse outcomes were not linked to running [15]. To date there has been little information about running patterns during pregnancy. One cross-sectional study explored training attitudes and behaviors in 110 female long-distance competitive runners during pregnancy [4]. A majority (70\%) ran during some time of the pregnancy but only $31 \%$ ran during the third trimester. Women who stopped running did so because they were uncomfortable, doctor advised them to stop, concern for miscarriage, and to maintain weight. Women had physical changes such as musculoskeletal disorders, ligamentous laxity, and increasing weight gain that negatively influenced their ability to run during pregnancy. Despite preliminary information related to running behaviors in competitive runners there have been no studies exploring running behaviors in pregnant women who self-identify as recreational runners.

The purpose of this study was to learn more about pregnant women who self-identified as runners, the barriers that kept them from running, and advice their health care providers offered in regards to running during their pregnancy. The information gathered here will contribute to what we know about running behaviors in pregnant women and will inform future research in addition to how health care providers can encourage and support women who run during pregnancy.

\section{Methods}

The Institutional Review Board of a large university in the southwestern United States approved this study, and all participants consented to the study.

\section{Participants}

Women were included in the study if they were 1) Currently pregnant or within one year post-partum, 2) Ran at any point during pregnancy, and 3) 18 years of age or older. Women were excluded if they could not read or understand English or were not pregnant OR not within one year post-partum. For this analysis, we only included currently pregnant women who reported running during their current pregnancy.

\section{Recruitment}

This was a national cross-sectional study using a purposive non-probabilistic sample. Research staff contacted organizations and social media sites (e.g., Facebook, Instagram) via email or directly through social media and asked them to post a flier to their website or social media site with a description of the study and a link to the eligibility survey. Recruitment for the study occurred between October 2016 and August 2017.

\section{Procedures}

Individuals interested in participating were asked to complete an online survey via Qualtrics (2005) that assessed whether they were eligible based on the three aforementioned inclusion criteria. After potential participants were confirmed eligible to participate, they were directed to the survey that assessed their running patterns (e.g. frequency, duration, intensity, reasons for terminating, etc.). The survey included a total of 136 possible questions which varied based on participants' responses, and took about 5-15 minutes to complete. The first 200 participants to complete the survey were compensated with a \$5 electronic gift card to Amazon. com.

\section{Survey}

Questions were developed by a high risk obstetrician and $\mathrm{PhD}$ trained researchers in exercise physiology and public health. Subsections of the survey included demographics; general information regarding the participants' health (i.e. height, weight, chronic health conditions) and pregnancy (i.e., trimester, parity); information regarding participants' running behaviors (i.e., number of days/miles/minutes per week by trimester) prior to, during, and/or post pregnancy; and changes in running patterns, including how participants altered their routines (i.e., intensity, distance, time, supplementation with other activities, etc.), when during pregnancy they altered, and who or what influenced them to alter (e.g., fatigue, joint pain, doctor, etc.) during pregnancy. There were also questions regarding participants' health care providers' recommendations about running. Examples of questions from each category can be found in Table 1 . 
Table 1: Survey Question Examples.

\begin{tabular}{|c|c|}
\hline Category & Example Question \\
\hline \multirow{3}{*}{ Demographics } & Have you been pregnant within the last year (within one year postpartum)? \\
\hline & $\begin{array}{l}\text { Do you currently run or have you run at any time during your current pregnancy and/ } \\
\text { or previous pregnancy (ies)? }\end{array}$ \\
\hline & What was your pre-pregnancy weight (in pounds)? \\
\hline \multirow{3}{*}{ Current pregnancy } & Currently, how many weeks pregnant are you? \\
\hline & How much weight have you gained thus far in your pregnancy? \\
\hline & Has your doctor classified your pregnancy as "high risk"? \\
\hline \multirow{3}{*}{$\begin{array}{l}\text { Running behavior in the year before } \\
\text { current pregnancy }\end{array}$} & $\begin{array}{l}\text { In the year before your current pregnancy, on average, how many times per week } \\
\text { did you run? }\end{array}$ \\
\hline & $\begin{array}{l}\text { In the year before your current pregnancy, on average, how many miles per week } \\
\text { did you run? }\end{array}$ \\
\hline & $\begin{array}{l}\text { In the year before your current pregnancy, on average, how many minutes per week } \\
\text { did you run? }\end{array}$ \\
\hline \multirow{3}{*}{ Running behavior in current pregnancy } & $\begin{array}{l}\text { On average, how many times per week did you run during the first trimester of your } \\
\text { current pregnancy (weeks 1-12)? }\end{array}$ \\
\hline & $\begin{array}{l}\text { During your current pregnancy, did you change your running patterns (e.g. miles, } \\
\text { time, pace, etc.)? }\end{array}$ \\
\hline & $\begin{array}{l}\text { Have your supplemented or replaced your running routine with a different type of } \\
\text { physical activity or intensity during your current pregnancy? }\end{array}$ \\
\hline \multirow{3}{*}{ Previous pregnancy } & When was your most recent previous pregnancy? \\
\hline & How much weight did you gain in your most recent previous pregnancy? \\
\hline & Did you breastfeed and/or pump during your most recent previous pregnancy? \\
\hline \multirow{3}{*}{$\begin{array}{l}\text { Running behaviors in the most recent } \\
\text { previous pregnancy }\end{array}$} & $\begin{array}{l}\text { During the year prior to your most recent previous pregnancy, how many times per } \\
\text { week on average did you run? }\end{array}$ \\
\hline & During your most recent previous pregnancy, did you change your running patterns? \\
\hline & Why did you change your running patterns in your most recent previous pregnancy? \\
\hline \multirow{3}{*}{ Health care provider questions } & $\begin{array}{l}\text { Did you have a conversation about running during pregnancy and/or post-partum } \\
\text { with your healthcare provider (e.g., OB/GYM, nurse practitioner)? }\end{array}$ \\
\hline & Specifically, what did your healthcare provider advise? \\
\hline & Were you satisfied with the advice that your healthcare provider gave you? \\
\hline
\end{tabular}

Table 2: Demographics and characteristics of pregnant women who reported running during their current pregnancy.

\begin{tabular}{|l|l|}
\hline Mean levels & M \pm SD \\
\hline Age & $31.9 \pm 4.2$ \\
\hline Weeks pregnant & $22.9 \pm 9.4$ \\
\hline Pregnancy weight gain (Ibs) & $22.6 \pm 34.3$ \\
\hline & \\
\hline Frequencies & $\%$ \\
\hline Hispanic & $20 \%$ \\
\hline Income & \\
\hline$\leq \$ 20,000$ & $0.6 \%$ \\
\hline$\$ 21,000-\$ 40,000$ & $5.5 \%$ \\
\hline \$41,000-\$60,000 & $7.7 \%$ \\
\hline$\$ 61,000-\$ 80,000$ & $14 \%$ \\
\hline$\$ 81,000-\$ 100,000$ & $33 \%$ \\
\hline$\geq \$ 101,000$ & $39 \%$ \\
\hline Married & $96 \%$ \\
\hline Physical Health & \\
\hline Excellent & $35 \%$ \\
\hline
\end{tabular}

\begin{tabular}{|l|l|}
\hline Very good & $54 \%$ \\
\hline Good & $8 \%$ \\
\hline Fair & $2 \%$ \\
\hline High risk pregnancy & $36 \%$ \\
\hline Times given birth & \\
\hline 0 & $21 \%$ \\
\hline 1 & $34 \%$ \\
\hline 2 & $24 \%$ \\
\hline $3+$ & $21 \%$ \\
\hline
\end{tabular}

\section{Statistical analysis}

Descriptive statistics (mean \pm standard deviation, frequencies, and percentages) were used to describe the general characteristics, reproductive history, running habits, change in running habits, and overall health in currently pregnant women. Analysis of variance was utilized to assess mean differences in running habits in women by pre-pregnancy body mass index (BMI) status and trimester with a Tukey test used for post-hoc analyses. Chi-squared tests were conducted to assess 
differences in categorical data. A P value of $<0.05$ was considered statistically significant. All analyses were conducted on SAS 9.4.

\section{Results}

Table 2 presents the demographics of currently pregnant women who reported running during their current pregnancy. The survey respondents were on average $31.9 \pm 4.2$ years of age, had a pre-pregnancy BMI of $23.9 \pm 3.8 \mathrm{~kg} / \mathrm{m}^{2}$ and $20 \%$ were Hispanic. Seventytwo percent of the sample reported income $>\$ 81,000$ per year and $96 \%$ were married. On average, women were $22.9 \pm 9.4$ weeks pregnant and had gained an average of $22.6 \pm 34.3 \mathrm{lbs}$. Thirty-six percent of women reported their current pregnancy as high risk and $21 \%$ of pregnant women had no prior pregnancies.

A total of 609 women completed the survey. Of these, 189 pregnant women reporting running during their current pregnancy. A total of 166 women changed their running during pregnancy. When asked when and why their running patterns changed during pregnancy (women could have chosen more than one answer), $73 \%(121 / 166)$ changed their running due to fatigue, $24 \%(39 / 166)$ due to pelvic pain and $18 \%(30 / 166)$ due to joint or muscle pain (Table 3). Of those who changed their patterns due to fatigue $(n=121)$, the majority $(71 \%$;

Table 3: Reasons why running patterns changed in currently pregnant women and when they changed.

\begin{tabular}{|l|l|l|l|}
\hline Frequencies & $\mathbf{n}$ & $\mathbf{( \% )}$ & $\begin{array}{l}\text { When patterns } \\
\text { changed }\end{array}$ \\
\hline Bleeding & 6 & $(3.6)$ & \\
\hline Breast Pain & 5 & $(3.0)$ & \\
\hline Child Care & 7 & $(4.0)$ & \\
\hline Contractions & 5 & $(3.0)$ & \\
\hline Doctor rec & 15 & $(9.0)$ & \\
\hline Fatigue & 121 & $(73.0)$ & $71 \%$ in $1^{\text {st }}$ trimester \\
\hline Incision pain & 2 & $(1.0)$ & \\
\hline Injury & 8 & $(5.0)$ & \\
\hline Joint or muscle & 30 & $(18.0)$ & $60 \%$ in $2^{\text {nd }}$ trimester \\
pain & 11 & $(7.0)$ & \\
\hline Lack of time & 11 & $(1.0)$ & \\
\hline Leak Gas & 2 & $(7.0)$ & \\
\hline Leak Urine & 11 & $(24.0)$ & $69 \%$ in $2^{\text {nd }}$ trimester \\
\hline Pelvic Pain & 39 & $(7.0)$ & \\
\hline Safety & 11 & & \\
\hline
\end{tabular}

86/121) did so in the first trimester. Of those women who changed their running patterns due to pelvic pain $(n=39)$, the majority $(69 \% ; 27 / 39)$ did so in the second trimester. Of those women who changed their patterns due to joint or muscle pain $(n=30)$, the majority $(60 \%$; 18/30) did so in the second trimester.

Women reported the average number of minutes running before and throughout pregnancy using predetermined ranges, which allowed for easier estimation while completing the survey (i.e., 0-30, 31$60,61-90,91-120,121-150,151+\mathrm{min} . / \mathrm{wk})$. The median value for the categories was determined and assigned as the continuous number of minutes completed. In the year before pregnancy, women reported running, on average, $100 \pm 42 \mathrm{~min} / \mathrm{wk}$. Throughout pregnancy women reported on average $77 \pm 42 \mathrm{~min} / \mathrm{wk}$ during the first trimester, $101 \pm 32 \mathrm{~min} / \mathrm{wk}$ during the second trimester and $49 \pm 44 \mathrm{~min} / \mathrm{wk}$ during the third trimester.

Table 4 presents the average minutes running before and throughout pregnancy by pre-pregnancy BMI status. During pre-pregnancy, underweight women reported significantly fewer minutes per week of running compared to normal, overweight and obese women ( $p$ $<0.001)$. The large difference is between underweight and overweight women during pre-pregnancy (57.1 minutes per week versus 116 minutes per week, respectively). Similarly, in the first trimester normal and overweight women reported running more than underweight women $(p=0.0045)$. There were no significant differences in number of minutes of running reported during the second trimester by pre-pregnancy BMI status. During the third trimester, underweight women reported running significantly more minutes per week than normal and overweight women $(p<0.001)$.

When asked about healthcare providers' recommendations, 75\% (142/189) had conversations with their health care providers (HCP) about running during pregnancy. Most (89\%) of these women initiated the conversation with their HCP. Women reported that a majority of their HCPs made a recommendation about running $(72.5 \%$; $103 / 142)$, while $20.4 \%$ (29/142) did not make a recommendation. It was reported that the specific advice from their HCP was (1) Do what you did prior to pregnancy $(36.9 \%, 38 / 103)$, (2) Decrease running (23.3\%, 24/103), (3) Change to another form of activity (13.6\%, 14/103), (4) Stop running $(12.6 \%, 13 / 103)$, or (5) Okay to increase running $(3.9 \%, 4 / 103)$. Ninety percent $(N=102 / 113)$ of the women who received advice

Table 4: Average number of minutes running before and throughout pregnancy by pre-pregnancy BMI status

\begin{tabular}{|l|l|l|l|l|}
\hline Mean levels & Pre-pregnancy $(\mathbf{M} \pm \mathbf{S D})$ & $\mathbf{1}^{\text {st }}$ trimester $(\mathbf{M} \pm \mathbf{S D})$ & $\mathbf{2}^{\text {nd }}$ trimester $(\mathbf{M} \pm \mathbf{S D})$ & $\mathbf{3}^{\text {rd }}$ trimester $(\mathbf{M} \pm \mathbf{S D})$ \\
\hline Underweight & $57.1 \pm 22.5$ & $55.3 \pm 26.2$ & $97.1 \pm 22.9$ & $86.5 \pm 25.6$ \\
\hline Normal & $110.1 \pm 40.4$ & $83.2 \pm 44.4$ & $100.4 \pm 37.7$ & $37.0 \pm 43.1$ \\
\hline Overweight & $116.8 \pm 36.2$ & $85.8 \pm 40.9$ & $112.7 \pm 29.0$ & $30.0 \pm 35.2$ \\
\hline Obese & $100.8 \pm 45.7$ & $81.7 \pm 44.4$ & $93.0 \pm 26.8$ & $50.0 \pm 55.0$ \\
\hline
\end{tabular}


from their HCP were satisfied with that information.

\section{Discussion}

The purpose of this study was to learn more about running behaviors in recreational runners during pregnancy, barriers that keep them from running, and advice their health care providers offered in regards to running during their pregnancy. The most common reason women changed their running patterns during pregnancy were due to fatigue (first trimester), pelvic pain, and joint or muscle pain (second trimester). The common modifications made to running during pregnancy were running more slowly, stopping running, adding walking, and running for shorter amounts of time. Women's running patterns decreased, on average, during the first trimester, increased during the second, and decreased again during the third. Underweight women reported running fewer minutes per week pre-pregnancy and the first trimester, but significantly more minutes during the third trimester as compared to normal and overweight women. Running minutes in the second trimester did not vary by weight status. Most women had conversations with their healthcare providers about running during pregnancy. The majority of healthcare providers made a recommendation about running and the majority of women were satisfied with the recommendation.

\section{Barriers to running}

Women in our study reported changes in running patterns during pregnancy and the barriers reported were different by trimester. In the first trimester, many women changed their running patterns due to fatigue, which is not surprising because women have reported experiencing the most fatigue during the first trimester [8]. In order of most frequently reported, women altered their running patterns by adding walking, running for less time, running more slowly, and stopping running all together. Based on our findings and the strong support from the literature for the positive effects of exercise on reduced levels of fatigue during pregnancy [18], the first trimester may be an opportune time for HCPs to educate pregnant women about the benefits of exercise to combat fatigue [19]. In women that identify themselves as a runner, HCPs may suggest altering running with activities such as walking, running slower, or running for a shorter amount of time when feeling fatigued.

Women in the second trimester who changed their running patterns did so mostly due to pelvic and/or joint pain and added walking to their running routines as a result. This is not surprising as pelvic and lowback pain are well known barriers to physical activity during pregnancy [9]. The second trimester may be a good time for HCPs to educate women who run during pregnancy, about the pain they may experience, especially what is normal versus abnormal pain, and make recommendations accordingly. Educating women about what to expect during each trimester and what types of modifications they might need to help them overcome barriers to exercise and may help them to continue exercise (i.e., running) during pregnancy.

Women's running minutes decreased, on average, during the first trimester, but increased during the second, and decreased again during the third. This inverted-U pattern is consistent with current literature on physical activity behavior during pregnancy $[2,11]$, however it differs slightly from other physical activity trajectory studies [13] and studies that focus on running, specifically, both of which found a linear decrease. In a study to describe the trajectories of physical activity in pregnant women, Huberty, et al. [11] reported pregnant women increased their physical activity in the first two trimesters but by the third trimester they spent more time sedentary and less time active.One reason that women in our study, and others, are able to increase activity in the second trimester could be due to a reduction of symptoms (e.g. nausea, fatigue) that are often reported as barriers to physical activity in the first trimester. In relation to a linear decrease in activity, Tenforde, et al. [4] found that pregnant women who run, despite their level of competition, decrease running as pregnancy progresses. Overall, regardless of the intensity of the activity as women are farther along in their pregnancies (end of second trimester and beginning of third trimester) physical activity participation decreases, women are not participating in recommended amounts of physical activity, and sedentary activity increases. Future studies should consider ways to reduce sedentary behavior during pregnancy, especially in the end of the second trimester and beginning of the third trimester. HCPs might recommend to their patients that they spend less time sitting, perhaps engaging lower intensity activities that are easily incorporated into their daily lives, with the goal of decreasing sedentary time [11].

\section{Weight status}

Underweight women in our study reported running fewer minutes per week pre-pregnancy and the first trimester, but significantly more minutes during the third trimester as compared to normal and overweight women. Running minutes in the second trimester did not vary by weight status. These differences may be due to preferences and ability by weight status as it relates to pregnancy. The literature regarding physical activity during pregnancy and its relation to $\mathrm{BMI}$ is inconclusive. One study found a negative relationship between BMI and activity level prior to pregnancy, however there was a substantial increase in activity level after becoming pregnant for women with higher BMIs [20]. A desire to control weight gain during pregnancy might explain why normal and overweight women reported more running minutes in the first trimester than underweight women 
in our study. Another study found that women with higher BMIs are more likely to decrease physical activity throughout pregnancy as compared to those with lower BMIs [21]. This inverse relationship might explain why underweight women in our study reported more running minutes than normal and overweight women during the third trimester. Perhaps overweight women are motivated to increase their physical activity levels after learning they are pregnant in hopes of improving birth outcomes, causing a spike in physical activity during the first trimester, but, like most women, do not sustain or further increase physical activity throughout pregnancy. There is a strong association between weight and joint pain due to mechanical stress, which might be another reason physical activity patterns decline in overweight women, especially during the third trimester [22]. This could suggest a need for information from the HCP to the patient about healthy gestational weight gain during pregnancy (i.e., recommendations for weight gain based on pre-pregnancy BMI) and how physical activity may play a role throughout pregnancy. It might also suggest a need for interventions regarding patient compliance with HCP recommendations. More research in this area is warranted to establish ways to help promote physical activity throughout pregnancy.

\section{Health care providers}

Pregnancy is an ideal time to implement physical activity interventions due to increased motivation and frequent interactions with health care providers [3]. Therefore, it is important for HCPs to be informed and educated to make appropriate recommendations for activity. HCPs need to be informed not only about what to recommend pregnant women for activity but also that prior activity plays a role in what a woman should/ should not do related to activity during pregnancy. For instance, Nascimento, et al. [2] found that pregnant women were more likely to engage in physical activity if they were already doing so prior to becoming pregnant. Therefore, exercise should be discussed with women during routine health care visits outside of pregnancy to promote healthy practices prior to pregnancy. Additionally, The American College of Obstetrics and Gynecology recommends HCPs utilize motivational counseling approaches to make recommendations regarding exercise during pregnancy, such as obtaining background information on exercise behaviors prior to becoming pregnant [3].

In this study, HCPs' recommendations to their patients about exercise were varied. HCPs may be making unique recommendations based on the woman's specific characteristics and symptoms, such as previous running behaviors, BMI, fitness level, reported pain, etc. Most likely, varied recommendations suggest lack of knowledge or difference of opinion among HCP providers regarding the safety of running in pregnancy [23]. Additionally, research has shown that because of tight clinical schedules and the lack of continuing medical education opportunities for training on prescribing prenatal physical activity, many providers lack knowledge about prenatal physical activity (e.g. contraindications, safety considerations), are unaware of the national recommendations for physical activity, lack confidence in their ability to prescribe physical activity and fail to talk with their sedentary pregnant patients about physical activity [23]. Because many women changed their running patterns throughout pregnancy, it would be beneficial for HCPs to be aware of how these patterns change in order to make women aware of these anticipated physical changes and challenges. For instance, if most women experience nausea during the first trimester, an HCP might suggest walking rather than a more vigorous alternative. If an $\mathrm{HCP}$ knows that running minutes typically increase again during the second trimester, he or she might advise it is common to increase running minutes.

\section{Conclusion}

The purpose of this study was to learn more about pregnant women who self-identify as runners, the barriers that keep them from running, and advice received from their HCPs in regards to running during pregnancy. The differences and reasons for change in running behavior by trimester indicates a need for HCPs to consider these changes when discussing running behavior with pregnant women as well as optimal times to intervene to promote continued physical activity throughout pregnancy. Changes in running behavior by weight status might suggest differences in preference and ability as well as changes in motivation between women. The findings from this study may help HCPs counsel patients regarding anticipated running changes during pregnancy. Future research is needed regarding the role of the HCP and the behaviors of pregnant women related to physical activity during pregnancy.

\section{Competing Interests}

No competing financial interests exist.

\section{Authors Contribution}

All authors contributed to the data collection, analysis, writing, and/or editing of this manuscript.

\section{References}

1. Ferraro ZM, Gaudet L, Adamo KB (2012) The potential impact of physical activity during pregnancy on maternal and neonatal outcomes. Obstetrical \& Gynecological Survey 67: 99-110.

2. Nascimento SL, Surita FG, Godoy AC, Kasawara KT, Morais SS (2015) Physical activity patterns and factors related to exercise during pregnancy: $A$ cross sectional study. PLoS One 10: e0128953.

3. American College of Obstetricians and Gynecologists, \& Committee on Obstetric Practice (2015) Physical activity and exercise during pregnancy and the postpartum period. Obstet Gynecol 126: e135-e142. 
4. Tenforde AS, Toth KE, Langen E, Fredericson M, Sainan $\mathrm{KL}$ (2015) Running habits of competitive runners during pregnancy and breastfeeding. Sports health 7: 172-176.

5. Evenson KR, Moos MK, Carrier K, Siega-Riz AM (2009) Perceived barriers to physical activity among pregnant women. Maternal and Child Health Journal 13: 364.

6. Evenson KR, Savitz A, Huston SL (2004) Leisuretime physical activity among pregnant women in the US. Paediatric and Perinatal Epidemiology 18: 400-407.

7. Harrison CL, Thompson RG, Teede HJ, Lombard CB (2011) Measuring physical activity during pregnancy. International Journal of Behavioral Nutrition and Physical Activity 8: 19.

8. Chou FH, Kuo SH, Wang RH (2008) A longitudinal study of nausea and vomiting, fatigue and perceived stress in, and social support for, pregnant women through the three trimesters. The Kaohsiung Journal of Medical Sciences 24: 306-314.

9. Santos PC, Abreu S, Moreira C, Lopes D, Santos R, et al. (2014) Impact of compliance with different guidelines on physical activity during pregnancy and perceived barriers to leisure physical activity. Journal of Sports Sciences 32: 1398-1408.

10. Downs DS, LeMasurier GC, DiNallo JM (2009) Baby steps: pedometer-determined and self-reported leisure-time exercise behaviors of pregnant women. Journal of Physical Activity and Health 6: 63-72.

11. Huberty JL, Buman MP, Leiferman JA, Bushar J, Adams MA (2016) Trajectories of objectively-measured physical activity and sedentary time over the course of pregnancy in women self-identified as inactive. Preventive Medicine Reports 3: 353-360.

12. Petersen AM, Leet TL, Brownson RC (2005) Correlates of physical activity among pregnant women in the United States. Medicine \& Science in Sports \& Exercise 37: 17481753.

13. Borodulin K, Evenson KR, Herring AH (2009) Physical activity patterns during pregnancy through postpartum. BMC Women's Health 9: 32.
14. Van Raaij JM, Schonk CM, Vermaat-Miedema SH, Peek ME, Hautvast JG (1991) Energy cost of lactation, and energy balances of well-nourished Dutch lactating women: reappraisal of the extra energy requirements of lactation. The American Journal of Clinical Nutrition 53: 612-619.

15. Evenson KR, Siega-Riz AM, Savitz DA, Leiferman JA, Thorp Jr JM (2002) Vigorous leisure activity and pregnancy outcome. Epidemiology 13: 653-659.

16. Oken E, Ning Y, Rifas-Shiman SL, Radesky JS, RichEdwards JW, et al. (2006) Associations of physical activity and inactivity before and during pregnancy with glucose tolerance. Obstetrics and Gynecology 108: 1200.

17. Sorensen G, Stoddard AM, Dubowitz T, Barbeau EM, Bigby $J$, et al. (2007) The influence of social context on changes in fruit and vegetable consumption: results of the healthy directions studies. American Journal of Public Health 97: 1216-1227.

18. Puetz TW, O'Connor PJ, Dishman RK (2006) Effects of chronic exercise on feelings of energy and fatigue: A quantitative synthesis. Psychological Bulletin 132: 866-876.

19. de Vries JD, van Hooff ML, Geurts SA, Kompier MA (2016) Exercise as an intervention to reduce study-related fatigue among university students: A two-arm parallel randomized controlled trial. PLoS One 11: e0152137.

20. Hinton PS, Olson CM (2001) Predictors of pregnancyassociated change in physical activity in a rural white population. Maternal and Child Health Journal 5: 7-14.

21. Fell DB, Joseph KS, Armson BA, Dodds L (2009) The impact of pregnancy on physical activity level. Maternal and Child Health Journal 13: 597.

22. Hartz AJ, Fischer ME, Bril G, Kelber S, Rupley Jr D, et al. (1986) The association of obesity with joint pain and osteoarthritis in the HANES data. Journal of Chronic Diseases 39: 311-319.

23. Leiferman J, Gutilla M, Paulson J, Pivarnik J (2012) Antenatal physical activity counseling among healthcare providers. Open Journal of Obstetrics and Gynecology 2. 